\title{
Analgesic Neural Circuits Are Activated by Electroacupuncture at Two Sets of Acupoints
}

\author{
Man-Li Hu, ${ }^{1}$ Zheng-Ying Qiu, ${ }^{1}$ Kuang $\mathrm{Hu}^{2}{ }^{2}$ and Ming-Xing Ding ${ }^{1}$ \\ ${ }^{1}$ College of Veterinary Medicine, Huazhong Agricultural University, Wuhan 430070, China \\ ${ }^{2}$ College of Life Science and Technology, Huazhong Agricultural University, Wuhan 430070, China \\ Correspondence should be addressed to Ming-Xing Ding; dmx@mail.hzau.edu.cn
}

Received 27 April 2016; Revised 3 June 2016; Accepted 5 June 2016

Academic Editor: Ke Ren

Copyright (c) 2016 Man-Li Hu et al. This is an open access article distributed under the Creative Commons Attribution License, which permits unrestricted use, distribution, and reproduction in any medium, provided the original work is properly cited.

\begin{abstract}
To investigate analgesic neural circuits activated by electroacupuncture (EA) at different sets of acupoints in the brain, goats were stimulated by EA at set of Baihui-Santai acupoints or set of Housanli acupoints for 30 min. The pain threshold was measured using the potassium iontophoresis method. The levels of c-Fos were determined with Streptavidin-Biotin Complex immunohistochemistry. The results showed pain threshold induced by EA at set of Baihui-Santai acupoints was $44.74 \% \pm 4.56 \%$ higher than that by EA at set of Housanli acupoints $(32.64 \% \pm 5.04 \%)$. Compared with blank control, EA at two sets of acupoints increased c-Fos expression in the medial septal nucleus (MSN), the arcuate nucleus (ARC), the nucleus amygdala basalis (AB), the lateral habenula nucleus (HL), the ventrolateral periaqueductal grey (vlPAG), the locus coeruleus (LC), the nucleus raphe magnus (NRM), the pituitary gland, and spinal cord dorsal horn (SDH). Compared with EA at set of Housanli points, EA at set of BaihuiSantai points induced increased c-Fos expression in AB but decrease in MSN, the paraventricular nucleus of the hypothalamus, $\mathrm{HL}$, and SDH. It suggests that ARC-PAG-NRM/LC-SDH and the hypothalamus-pituitary may be the common activated neural pathways taking part in EA-induced analgesia at the two sets of acupoints.
\end{abstract}

\section{Introduction}

Electroacupuncture (EA), a widely used version of acupuncture which provides a stimulating current to acupoints through acupuncture needles, is effective and quantifiable. Electroacupuncture-induced analgesia (EAA) has been applied to ameliorate pain not only in varieties of painful diseases [1-4], but also in various operations, such as cesarean section, gastrectomy, enterectomy, and castration in humans or animals during the 1970s [5-7]. Some researchers used classical physical approaches (the stimulation and abolition of certain nerve fibres or nuclei) as well as pharmacological approaches (assessing antagonists and antibodies) to identify that EAA is involved in some cerebral nuclei or areas such as the nucleus amygdala (AMY), the periaqueductal grey (PAG), and the locus coeruleus (LC) [8-12]. Because nuclei are linked to each other with their fibres and constitute a complex network, the function of a single nucleus or area cannot elucidate the neural mechanism underlying EAA. Functional magnetic resonance imaging (fMRI) has been used to explore the cerebral regions activated by EA. Chiu et al. [13] found a tendency for the activation of painmodulation areas induced by EA at bilateral Hegu or Zusanli acupoints was prominent as compared with EA stimulation at bilateral Neiguan acupoints in rats through fMRI. Similarly, it has been demonstrated that EA at different acupoints can elicit different fMRI-activated patterns in the human brain $[14,15]$. These studies indicate that the central activated regions are acupoint-dependent. However, EAA-related neural circuitries activated by EA at different sets of acupoints are not clear yet.

C-fos, an immediate early gene, is expressed at low levels in the intact brain under basal conditions and responses rapidly and transiently after various stimulations, including restraint $[16,17]$, noise $[17,18]$, and pain [19]. Its protein product, Fos, as a marker, has been used to reveal functional heterogeneity among neuronal subpopulations [20] and map neuronal pathways in the central nervous system (CNS). In addition, c-Fos protein is a part of transcription factor AP-1 involved in the regulation of target genes when cells 
become activated. The verified target genes of c-Fos include active substances participating in EAA in the CNS, such as preproenkephalin $[21,22]$, proopiomelanocortin $[23,24]$, preprodynorphin [25], 5-TH receptors [26], and cholecystokinin [27].

It has been demonstrated that EAA varies in species [2830]. These studies have shown that EA in combination with analgesics reduces the required dose of analgesics in humans [30], rats [29], and goats [28] by $48 \%, 50 \%$, and over $75 \%$, respectively. It is clear that the analgesic effect induced by EA in goats (ruminants) is superior to that in humans or rats if the species or the analgesic properties are not considered. Ruminants can be optimal model animals for investigating the mechanisms underlying EAA. In the present study, to explore central neural mechanism by which EA induces analgesia, goats were stimulated by EA at two sets of acupoints, and the expression levels of c-Fos were measured in analgesia-related nuclei or areas, including the caudate nucleus (CAU), the nucleus accumbens (ACB), the lateral septal nucleus (LSN), the medial septal nucleus (MSN), the paraventricular nucleus of the hypothalamus (PVH), the ventromedial nucleus of the hypothalamus (VMH), the arcuate nucleus (ARC), the nucleus amygdala basalis $(\mathrm{AB})$, the lateral habenula nucleus (HL), the caudal ventrolateral periaqueductal grey (vlPAG), the parabrachial nucleus $(\mathrm{PBN})$, LC, the nucleus raphe magnus (NRM), the gigantocellular reticular nucleus (GI), the nucleus tractus solitarius (NTS), the anterior lobe of the pituitary gland (PG), and spinal cord dorsal horn (SDH). It is hypothesized that there exist common neural circuits among the analgesia-related nuclei or areas activated by sets of acupoints.

\section{Materials and Methods}

2.1. Animals. One-year-old healthy crossbred male goats $(30 \pm 2 \mathrm{~kg}$ body wt, $n=28)$ were purchased from Hubei Agricultural Academy of Science. The goats were randomly assigned for 4 treatments: the blank control, the sham control, EA at Baihui and Santai acupoints, and EA at bilateral Housanli acupoints, 7 goats per group. The goats were housed in the same management condition with food and water ad libitum. A quiet environment was provided, and the room temperature was maintained $22 \pm 2^{\circ} \mathrm{C}$ during experiment. Experimental animals were accustomed to being approached and restrained ( $1 \mathrm{~h} /$ day) for two weeks before the start of the experiment. The experimental protocol (HZAUGO-2015005) was approved by the Animal Care Center, College of Veterinary Medicine, Huazhong Agricultural University (Wuhan, China).

2.2. Electroacupuncture Procedures. For EA stimulation, the set of Baihui and Santai acupoints and the set of bilateral Housanli acupoints (equal to Zusanli in humans) were selected for two EA groups. Here the acupoints are nominated with Pinyin Naming System instead of the Meridian Numbering System because animal's meridians are not completely recorded. The anatomical locations of these acupoints have been described in detail for use in veterinary medicine
[28, 31-33]. The Baihui acupoint was identified on the dorsal midline between the spinous processes of the last lumbar and the first sacral vertebrae. The Santai acupoint was identified on the dorsal midline between the spinous processes of the fourth and fifth thoracic vertebrae. The Housanli acupoint was identified in the muscular groove between the long digital extensor and the lateral digital extensor muscles below the head of the fibula on the bilateral lateral surface of the bilateral legs. The needles were disinfected and inserted into the acupoints by a skilled acupuncturist after acupoint sites were shaved and disinfected with $75 \%$ ethanol. A stainless steel acupuncture needle $(0.40 \mathrm{~mm}$ in diameter and $50 \mathrm{~mm}$ in length) was perpendicularly inserted into the Baihui acupoint to a depth of approximately $30 \mathrm{~mm}$. For the Santai acupoint, a needle $(0.45 \mathrm{~mm}$ in diameter and $75 \mathrm{~mm}$ in length) was inserted into the acupoint to a depth of 40 to $50 \mathrm{~mm}$ at a $45^{\circ}$ angle. For bilateral Housanli acupoints, two needles $(0.40 \mathrm{~mm}$ in diameter and $50 \mathrm{~mm}$ in length) were perpendicularly inserted into each point to a depth of 20 to $30 \mathrm{~mm}$. The needles in each set of EA group were connected by a pair of wires to one output of WQ-6F Electronic Acupunctoscope (Beijing Xindonghua Electronic Instrument Co., Ltd., Beijing, China). According to Cheng et al. [33], the goats were treated with EA of $60 \mathrm{~Hz}$ and $3.2 \mathrm{~V}$ for $30 \mathrm{~min}$. Needles were inserted into Baihui and Santai acupoints of the goats without electricity as the sham control. The goats were restrained in the same manner as EA-stimulated goats without needling and EA as the blank control.

2.3. Determination of Pain Threshold. Pain threshold was assessed immediately before and after EA administration by one skilled person who was blinded to the goat assignments. The pain was induced by potassium iontophoresis $[28,34$, 35] passing through the skin by a direct current induction therapy apparatus (Shantou Medical Equipment Factory Co., Ltd., Shantou, China). The site was shaved and cleaned with soap and water and sterilized with $75 \%$ ethanol. Two electrodes were soaked with saturated potassium chloride and placed $1-2 \mathrm{~cm}$ apart on the center of the left flank skin. The pulse direct current delivered potassium ions into the subcutaneous tissues while voltage was continuously increased. When obvious contraction of the local skin and muscle along with head turning toward the abdomen, back hunching, and body eluding movement were observed, the voltage level was recorded. The procedure was repeated three times with $5 \mathrm{~min}$ interval. Mean voltages before and after EA were expressed as $V_{0}$ and $V_{n}$, respectively. The change of percentage in pain threshold was calculated by the following formula: $\Delta \%=\left(V_{n}-V_{0}\right) / V_{0} \times 100 \%$.

2.4. Immunohistochemistry. The levels of c-Fos protein were measured through the method of SABC immunohistochemistry. Once the pain threshold was measured after EA, experimental goats were deeply anesthetized with intravenous administration of xylidinothiazoline at $3 \mathrm{mg} / \mathrm{kg}$. Physiological saline was infused through bilateral carotid arteries while the blood flowed out from the jugular veins. When the liquid became transparent, $4 \%$ percent paraformaldehyde 


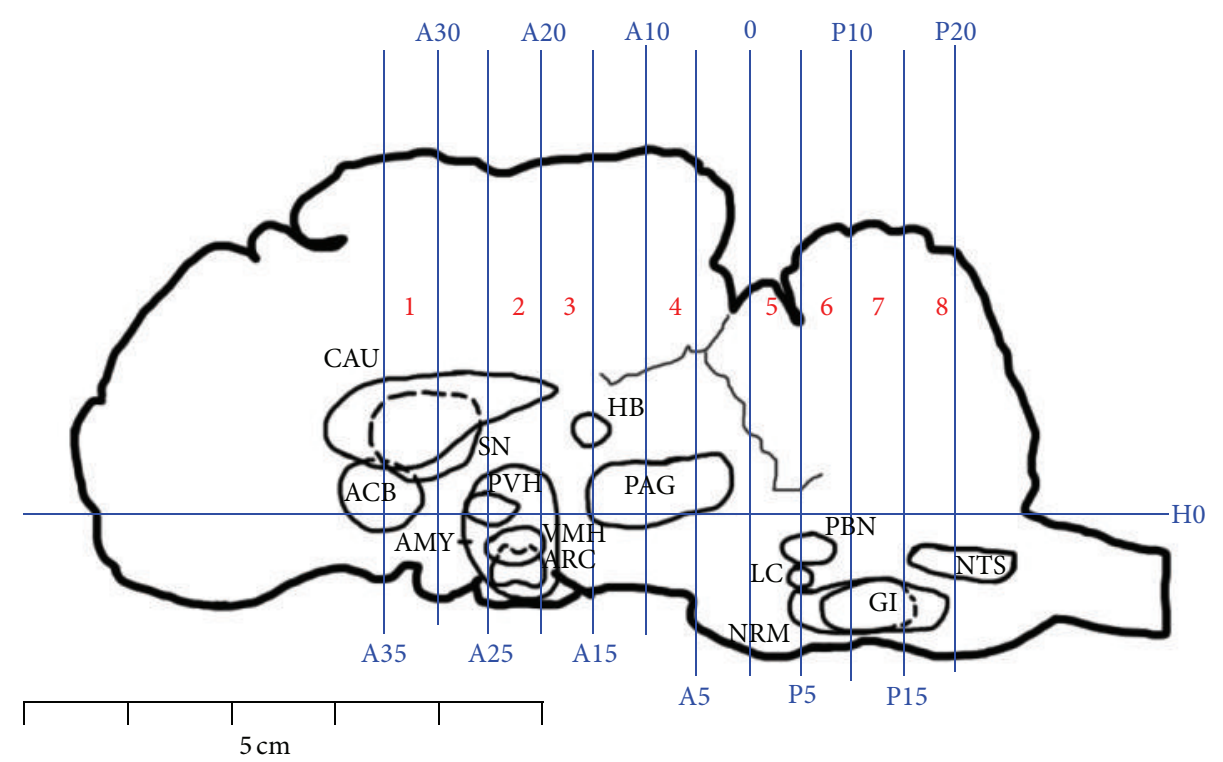

FIGURE 1: Brain sectioning. H0: the horizontal zero plane. A35, A30, A25, A20, A15, A10, A5, and 0 show transverse planes at 35, 30, 25, $20,15,10,5$, and $0 \mathrm{~mm}$ rostral to the interaural line, and P5, P10, P15, and P20 show transverse planes at 5, 10, 15, and 20 mm caudal to the interaural line, respectively. The nuclei and areas identified include the nuclei or areas to be observed were the caudate nucleus (CAU), the nucleus accumbens (ACB), the septal nucleus (SN), the paraventricular nucleus of the hypothalamus (PVH), the ventromedial nucleus of the hypothalamus (VMH), the arcuate nucleus (ARC), and the amygdala (AMY), the nucleus habenula (HB), the periaqueductal grey (PAG), the parabrachial nucleus (PBN), the locus coeruleus (LC), the nucleus raphe magnus (NRM), the gigantocellular reticular nucleus (GI), and the nucleus tractus solitarius (NTS).

instead of the physiological saline was infused for $1 \mathrm{~h}$. The pituitary gland, brain, and a part of the cervical spinal cord $\mathrm{Cl}$ were taken out of the skull and cervical vertebral canal. The brain was transected into 8 blocks (B 1-8) with the method described by Qiu et al. [31]. The vertical interaural plane represented the zero reference point for the anteriorposterior coordinates, and the horizontal zero plane (H0) intersected the interaural point and a point $25 \mathrm{~mm}$ above the lower margin of the orbit. Blocks B1-B8 are from anterior $35 \mathrm{~mm}$ (A35) to anterior $30 \mathrm{~mm}$ (A30), anterior $25 \mathrm{~mm}$ (A25) to anterior $20 \mathrm{~mm}$ (A20), anterior $20 \mathrm{~mm}(\mathrm{~A} 20)$ to anterior $15 \mathrm{~mm}$ (A15), anterior $10 \mathrm{~mm}$ (A10) to anterior $5 \mathrm{~mm}$ (A5), $0 \mathrm{~mm}$ (0) to posterior $5 \mathrm{~mm}$ (P5), posterior $5 \mathrm{~mm}$ (P5) to posterior $10 \mathrm{~mm}(\mathrm{P} 10)$, posterior $10 \mathrm{~mm}$ (P10) to posterior $15 \mathrm{~mm}$ (P15), and posterior $15 \mathrm{~mm}$ (P15) to posterior $20 \mathrm{~mm}$ (P20), respectively (Figure 1$)$.

The nuclei or areas were identified according to the brain atlas of goats and pigs and the morphological characteristics of the neurons [36-39]. The nuclei or areas to be observed were the CAU, ACB, LSN, and MSN in B1, the PVH, VMH, $A R C$, and $A B$ in $B 2$, the $H L$ in the caudal part of $B 3$, the vlPAG in $\mathrm{B} 4$, the PBN and the LC between the caudal part of B5 and the rostral part of B6, the NRM and GI in B7, and the NTS in B8 (Figure 1). The blocks were embedded in paraffin with their rostral surface facing up. Each of the blocks was consecutively sectioned with a thickness of $5 \mu \mathrm{m}$. Four slides of each nucleus or brain area were mounted on polylysine coated slides, deparaffinized, and rehydrated sequentially. Among these four slides, three of them were incubated with rabbit-anti-c-Fos (Wuhan Boster Biological Technology Ltd., Wuhan, China; 1:50 diluted in PBS) while one was incubated with PBS instead of the antibody as the negative control. The remaining experimental procedures of SABC immunohistochemistry followed the instructions provided by the reagent company (Wuhan Boster Biological Technology Ltd., Wuhan, China). The nucleus of positive cells was stained as brown yellow. The locations of the observed nuclei (areas) with the representative stained cells are shown in Figure 2.

Optical images of the stained nuclei or area in the CNS were obtained under a light microscope (Nikon ECLIPSE 80I, Nikon Corporation, and Tokyo, Japan) connected to a video-based and computer-linked system (high-resolution pathological image analysis system 1000, Wuhan Qianping Ltd., Wuhan, China). Three slides of each nucleus or brain area were observed with 200x magnification on both sides. The number of c-Fos-like immunoreactive (c-Fos-IR) cells on each nucleus or brain area was counted by the ImagePro plus 6.0 system (MediaCybernetics, Inc., Bethesda, MD, USA). The mean values calculated from each nucleus or brain area represented the c-Fos-IR cells per goat.

2.5. Statistical Analysis. All data were presented as the mean \pm SD. Data analysis was performed with SPSS 18.0 software (SPSS Inc., Chicago, USA). The pain threshold and the number of c-Fos-IR cells were analyzed using one-way ANOVA, followed by Bonferroni's post hoc test. The value of $p<0.05$ was considered to be significant. 


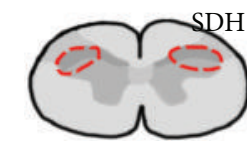

$1 \mathrm{~cm}$

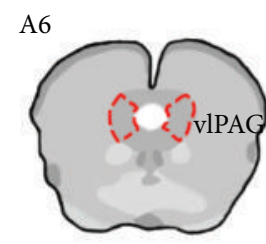

$1 \mathrm{~cm}$

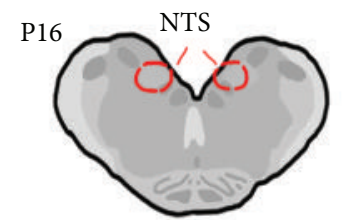

$1 \mathrm{~cm}$

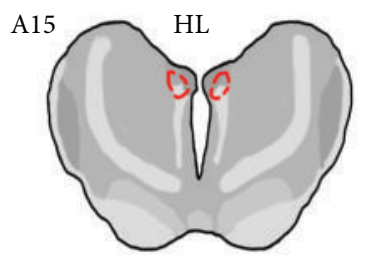

$2 \mathrm{~cm}$
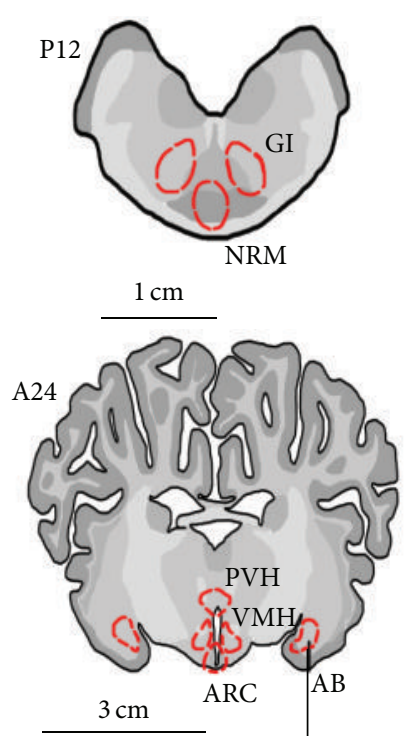

(a)

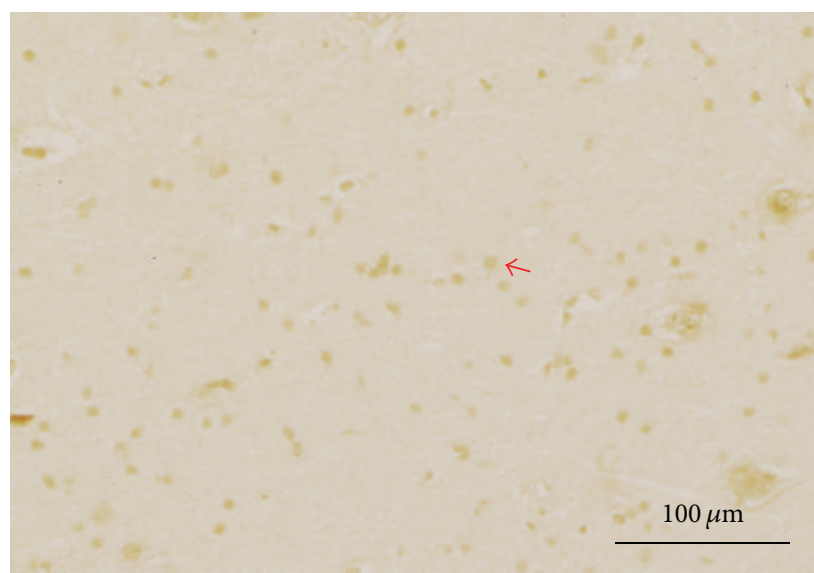

(c)
$100 \mu \mathrm{m}$

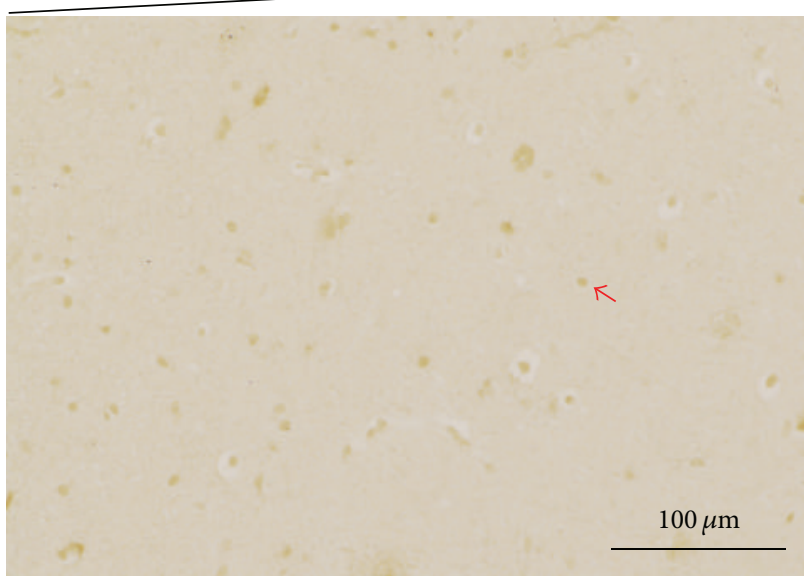

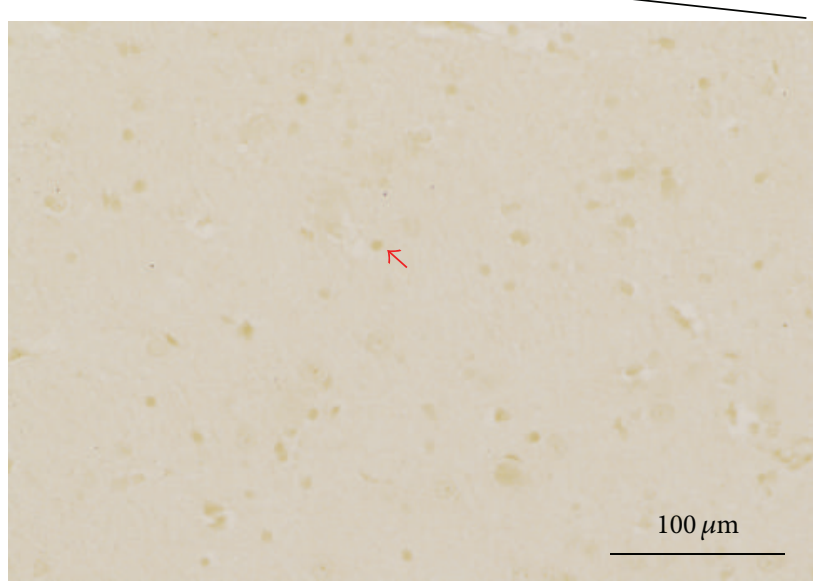

(b)

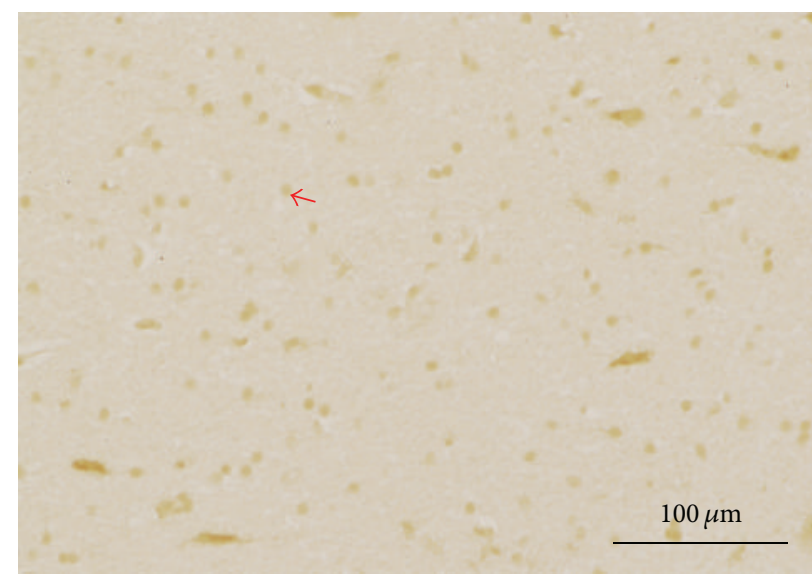

(d)

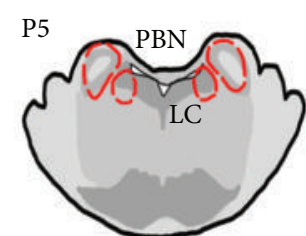

$1 \mathrm{~cm}$

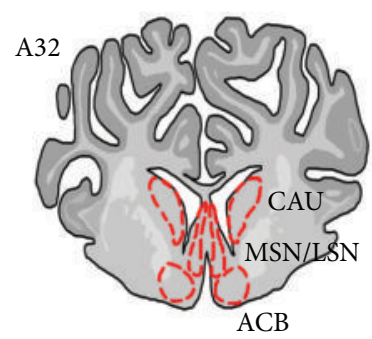

$3 \mathrm{~cm}$

Figure 2: The nuclei (areas) locations used for the c-Fos-like immunoreactive (c-Fos-IR) neurons counts and the representative c-Fos-IR neurons in AB. C1: spinal cord dorsal horn (SDH). P16: NTS at interaural levels of $-16 \mathrm{~mm}$. P12: NRM and GI at interaural levels of $-12 \mathrm{~mm}$. P5: PBN and LC at interaural levels of $-5 \mathrm{~mm}$. A6: the ventrolateral periaqueductal grey (vlPAG) at interaural levels of $6 \mathrm{~mm}$. A15: the lateral habenula nucleus (HL) at interaural levels of $16 \mathrm{~mm}$. A24: PVH, VMH, ARC, and nucleus amygdala basalis (AB) at interaural levels of $24 \mathrm{~mm}$. A32: ACB, CAU, the lateral septal nucleus (LSN), and the medial septal nucleus (MSN) at interaural levels of $32 \mathrm{~mm}$. (a)-(d) show positive c-Fos-IR neurons in AB in the blank control, sham control, EA at the set of bilateral Housanli acupoints, and the set of Santai and Baihui acupoints, respectively. Arrows point to the positive neurons. The bars $=100 \mu \mathrm{m}$. 


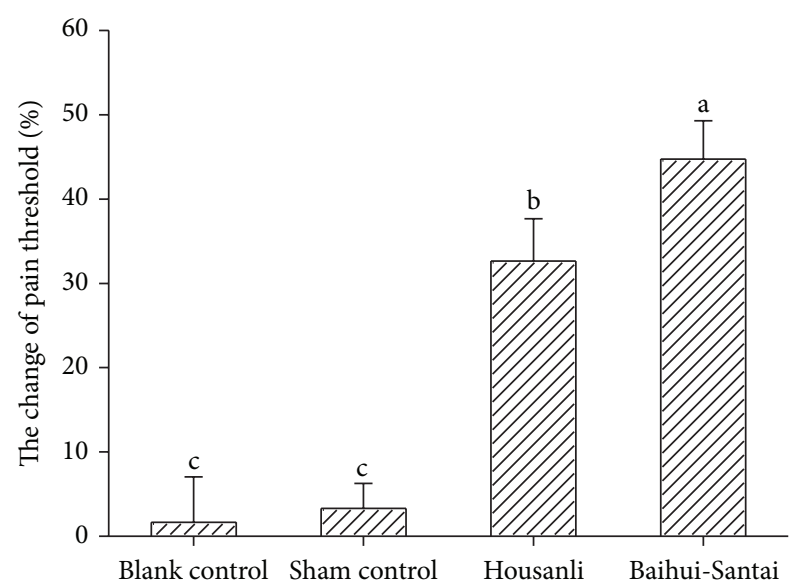

FIgUre 3: Analgesic effects induced by EA in goats (mean \pm SD, $\%, n=7$ ). The pain thresholds were measured with potassium iontophoresis. EA significantly increased pain threshold. The values with different letters differ significantly $(p<0.05)$. The blank control refers to the group in which the goats were restrained as the EAtreated goats without needling and electric stimulation. The sham control refers to the group in which needles were inserted into Baihui and Santai acupoints of the goats without electric stimulation.

\section{Results}

3.1. Analgesic Effects Induced by Electroacupuncture. The EAA effects were represented by the changes in the pain threshold (Figure 3$)$. No significant difference $(p=1.000)$ in the pain threshold was found between the blank control $(1.64 \% \pm 5.39 \%)$ and the sham control $(3.29 \% \pm 2.96 \%)$. Compared with the blank control, the pain threshold in the two EA groups increased $(p<0.05)$. The pain thresholds in goats treated with EA at the set of Baihui and Santai acupoints and at the set of bilateral Housanli acupoints increased by $44.74 \% \pm 4.56 \%$ and $32.64 \% \pm 5.04 \%$, respectively, with the former significantly higher $(p=0.001)$ than the latter.

3.2. The Expression Levels of c-Fos Induced by EA. C-FosIR cells were observed in the analgesia-related nuclei and areas, which included CAU, ACB, LSN, MSN, PVH, VMH, ARC, AB, HL, vlPAG, PBN, LC, NRM, GI, NTS, PG, and SDH (Table 1$)$. There was no difference $(p>0.05)$ in the number of c-Fos-IR cells between the blank control and the sham control. Compared with the blank control, c-Fos-IR cells in goats treated with EA at the set of bilateral Housanli acupoints increased $(p<0.05)$ in the LSN, MSN, PVH, VMH, ARC, AB, HL, vlPAG, PBN, LC, NRM, GI, PG, and $\mathrm{SDH}$, while $\mathrm{c}$-Fos-IR cells in goats receiving EA at the set of Baihui and Santai acupoints increased $(p<0.05)$ in the MSN, VMH, ARC, AB, HL, vlPAG, PBN, LC, NRM, GI, PG, and $\mathrm{SDH}$. Compared with EA at the set of bilateral Housanli acupoints, EA at the set of Baihui and Santai acupoints induced c-Fos-IR cells to increase $(p<0.05)$ in the AB, but to decrease $(p<0.05)$ in the MSN, PVH, HL, and SDH.

\section{Discussion}

Numerous studies and clinical practices have shown that EA can induce potent analgesia. Wang et al. [40] used EA to stimulate bilateral Zusanli and Kunlun acupoints in rabbits and found that better analgesia was induced by $2 \mathrm{~Hz}$, followed by $30 \mathrm{~Hz}>60 \mathrm{~Hz}>100 \mathrm{~Hz}$. Wang et al. [41] reported that $100 \mathrm{~Hz}$ EA at bilateral Zusanli and Sanyinjiao acupoints induced more effective analgesia than $2 \mathrm{~Hz}$ in rats. Cao et al. [42] reported that $15 \mathrm{~Hz} \mathrm{EA}$ at bilateral Yanglingquan acupoints induced more effective analgesia than $100 \mathrm{~Hz}$ EA in rats. In goats, Cheng et al. [33] compared analgesic effects induced by $0,2,40,60,80$, and $100 \mathrm{~Hz}$ of EA for $30 \mathrm{~min}$ and found that $60 \mathrm{~Hz}$ produced more potent analgesia than any other frequency did. These studies show that EA-induced analgesic effect varies in different frequencies in the specific species. Acupoint is another important factor influencing EAA. Studies have demonstrated that EA stimulation at a set of Baihui and Santai acupoints can elicit an effective analgesia in goats [28, 31-33]. Zusanli acupoint has been widely used to induce analgesic effect in rats [8], rabbits [40], and humans [4]. In the present study, pain thresholds in goats receiving $60 \mathrm{~Hz}$ of EA at the set of Baihui and Santai acupoints and the set of bilateral Housanli acupoints for $30 \mathrm{~min}$ were increased by $44.74 \% \pm 4.56 \%$ and $32.64 \% \pm 5.04 \%$, respectively, showing different analgesic effects induced by these two sets of acupoints.

Functional magnetic resonance imaging studies illustrated that the limbic and paralimbic structures of the cortical and subcortical regions in the telencephalon, the brainstem, and the cerebellum were excited after acupuncture was administered at bilateral Zusanli acupoints in human, showing that acupuncture-induced activated networks exist in the CNS [43]. However, the analgesia-related neural circuits activated by EA are not elucidated. Jang-Hern and Beitz [44] reported that EA of $4 \mathrm{~Hz}$ at bilateral Zusanli acupoints activated c-Fos-IR neurons in the PBN, LC, PAG, ARC, the habenula nucleus (HB), the substantia nigra (SNC), nucleus raphe pallidus, posterior pretectal nucleus, the cuneiform nucleus, the lateroventral and lateral hypothalamic nuclei, and $\mathrm{SDH}$ in rats, while EA of $100 \mathrm{~Hz}$ activated the PBN, LC, PAG, SNC, nucleus raphe pallidus, posterior pretectal nucleus, rostolateroventral nucleus of the medulla, and SDH. In our study, EA of $60 \mathrm{~Hz}$ at the set of bilateral Housanli acupoints activated the LSN, MSN, PVH, VMH, ARC, AB, HL, vlPAG, PBN, NRM, LC, GI, PG, and SDH. These studies suggest that EA specific circuits in the CNS might be mediated by different frequencies. Qiu et al. [31] indicated that EA of $60 \mathrm{~Hz}$ at Baihui, Santai, Ergen, and Sanyangluo acupoints induced increased c-Fos-IR neurons in the ACB, LSN, CAU, PVH, AB, ARC, HL, vlPAG, PBN, LC, NRM, NTS, GI, SNC, and the supraoptic nucleus in goats. We used EA of $60 \mathrm{~Hz}$ at the set of Baihui and Santai acupoints and found that the MSN, VMH, ARC, AB, HL, vlPAG, PBN, NRM, LC, GI, PG, and SDH were activated in goats. These show that the two sets of acupoints can activate more complex neural networks compared with one set of acupoints. Therefore, analysis of discrepancy in the activated cerebral nuclei or areas by EA at two sets of acupoints is useful for exploring the 
TABLE 1: The number of c-Fos-like immunoreactive cells in the nuclei or areas after goats received EA at two sets of acupoints (mean \pm SD, number $\times 10^{-1} /$ field, $n=7$ ).

\begin{tabular}{|c|c|c|c|c|}
\hline Nuclei and areas & Blank control & Sham control & EA at Housanli & EA at Baihui-Santai \\
\hline CAU & $9.88 \pm 2.08$ & $8.23 \pm 1.35$ & $9.91 \pm 1.65$ & $8.40 \pm 1.30$ \\
\hline $\mathrm{ACB}$ & $9.18 \pm 0.99$ & $8.09 \pm 0.88^{\mathrm{b}}$ & $10.14 \pm 1.55^{\mathrm{a}}$ & $10.96 \pm 1.42^{\mathrm{a}}$ \\
\hline LSN & $12.90 \pm 1.98^{\mathrm{b}}$ & $12.33 \pm 1.46^{\mathrm{b}}$ & $15.70 \pm 0.77^{\mathrm{a}}$ & $14.60 \pm 1.90$ \\
\hline MSN & $10.64 \pm 1.64^{c}$ & $10.86 \pm 1.86^{\mathrm{c}}$ & $17.07 \pm 1.45^{\mathrm{a}}$ & $14.41 \pm 1.71^{\mathrm{b}}$ \\
\hline $\mathrm{PVH}$ & $13.07 \pm 0.89^{\mathrm{b}}$ & $13.03 \pm 1.76^{\mathrm{b}}$ & $18.42 \pm 1.94^{\mathrm{a}}$ & $14.40 \pm 1.85^{\mathrm{b}}$ \\
\hline VMH & $8.93 \pm 0.78^{b}$ & $8.95 \pm 0.86^{\mathrm{b}}$ & $14.31 \pm 1.05^{\mathrm{a}}$ & $14.84 \pm 1.74^{\mathrm{a}}$ \\
\hline $\mathrm{AB}$ & $8.50 \pm 1.10^{c}$ & $8.27 \pm 0.91^{\mathrm{c}}$ & $11.61 \pm 2.69^{b}$ & $15.35 \pm 2.22^{\mathrm{a}}$ \\
\hline ARC & $16.72 \pm 1.59^{\mathrm{b}}$ & $17.27 \pm 1.55^{\mathrm{b}}$ & $22.20 \pm 2.15^{\mathrm{a}}$ & $23.17 \pm 1.04^{\mathrm{a}}$ \\
\hline $\mathrm{HL}$ & $8.58 \pm 0.90^{c}$ & $8.28 \pm 1.84^{c}$ & $15.39 \pm 2.34^{\mathrm{a}}$ & $12.22 \pm 0.75^{\mathrm{b}}$ \\
\hline vlPAG & $12.81 \pm 0.62^{\mathrm{b}}$ & $12.89 \pm 1.37^{\mathrm{b}}$ & $16.04 \pm 0.88^{\mathrm{a}}$ & $16.70 \pm 0.68^{\mathrm{a}}$ \\
\hline PBN & $9.38 \pm 1.06^{\mathrm{b}}$ & $10.84 \pm 1.08^{\mathrm{b}}$ & $14.12 \pm 0.96^{\mathrm{a}}$ & $14.30 \pm 1.29^{\mathrm{a}}$ \\
\hline LC & $9.31 \pm 2.39^{\mathrm{b}}$ & $10.16 \pm 1.60^{\mathrm{b}}$ & $13.65 \pm 1.06^{\mathrm{a}}$ & $15.27 \pm 2.40^{\mathrm{a}}$ \\
\hline NRM & $6.68 \pm 0.78^{b}$ & $7.19 \pm 1.45^{\mathrm{b}}$ & $11.56 \pm 2.21^{\mathrm{a}}$ & $11.15 \pm 2.67^{\mathrm{a}}$ \\
\hline NTS & $12.40 \pm 0.81$ & $11.74 \pm 1.99$ & $12.34 \pm 1.55$ & $11.15 \pm 1.33$ \\
\hline GI & $4.35 \pm 1.70^{\mathrm{b}}$ & $4.78 \pm 1.65$ & $7.91 \pm 0.95^{\mathrm{a}}$ & $7.88 \pm 2.04^{\mathrm{a}}$ \\
\hline PG & $30.37 \pm 14.23^{\mathrm{b}}$ & $30.56 \pm 8.31^{\mathrm{b}}$ & $51.23 \pm 4.43^{\mathrm{a}}$ & $49.79 \pm 10.14^{\mathrm{a}}$ \\
\hline $\mathrm{SDH}$ & $8.21 \pm 1.18^{\mathrm{c}}$ & $8.96 \pm 0.93^{c}$ & $14.12 \pm 0.92^{\mathrm{a}}$ & $12.35 \pm 0.94^{\mathrm{b}}$ \\
\hline
\end{tabular}

Values with different letters in the same row differ significantly $(p<0.05)$. The blank control refers to the group in which the goats were restrained as the EAtreated goats without needling and electric stimulation. The sham control refers to the group in which needles were inserted into Baihui and Santai acupoints of the goats without electric stimulation. The nuclei and areas are presented as follows: the caudate nucleus (CAU), the nucleus accumbens (ACB), the lateral septal nucleus (LSN), the medial septal nucleus (MSN), the paraventricular nucleus of the hypothalamus (PVH), the ventromedial nucleus of the hypothalamus $(\mathrm{VMH})$, the arcuate nucleus (ARC), the nucleus amygdala basalis (AB), the lateral habenula nucleus (HL), the ventrolateral periaqueductal grey (vlPAG), the parabrachial nucleus (PBN), the locus coeruleus (LC), the nucleus raphe magnus (NRM), the gigantocellular reticular nucleus (GI), the nucleus tractus solitarius (NTS), the anterior lobe of the pituitary gland (PG), and spinal cord dorsal horn (SDH).

neural mechanism underlying EAA. Chae et al. [45] found that c-Fos-IR neurons activated by EA at bilateral Taiyuan acupoints were less than those by EA at bilateral Shenmen or Zusanli acupoints in the shell of ACB and that c-FosIR neurons induced by EA at bilateral Shenmen acupoints were less than those by EA at bilateral Taiyuan or Zusanli acupoints in the ventromedial of the striatum in repeated nicotine-induced behavioral sensitization rats. In the present study, c-Fos-IR neurons activated by EA at the set of Baihui and Santai acupoints were significantly different from EA at the set of bilateral Housanli acupoints in the MSN, PVH, AB, $\mathrm{HL}$, and SDH. These studies suggest the cerebral nuclei and areas activated by EA are acupoint-dependent.

Researchers have done a lot of work to confirm the analgesia-related neural circuits with the stimulation and abolition of certain nerve fibres or nuclei as well as pharmacological approaches (assessing antagonists and antibodies). Several lines of evidence have shown that the PAG, one of the regions contributing to the endogenous pain inhibitory system $[16,46]$ and being involved in the analgesic effect of acupuncture $[47,48]$, projects to the RVM (mainly NRM) [49] and the LC [50]. Mokha et al. [51] identified that the NRM and LC mediated spinal nociceptive transmission through independent descending inhibitory pathways. Ao et al. [52] found that electroacupuncture could activate excitatory neurons in RVM. Several studies suggested that EA activated RVM might inhibit pain through a descending serotonergic system in the spinal cord [53, 54]. A classical study found that electrical stimulation of the LC caused a moderate attenuation [12] while the electrolytic lesion of the LC induced potentiation of acupuncture. These studies suggest that PAG-NRM/LC-SDH pathway constitutes the descending inhibitory pathway for EAA.

In addition, some studies have verified that pain regulation is involved in limbic system (AMY, HB, and ARC) midbrain (PAG) pathway. Functional MRI studies showed that the limbic system played a major role in regulation of EA analgesia [55-57]. The AMY sends neuronal projections to PAG [58-60] which in turn projects to analgesic modulating neurons in the RVM [49]. The study of Tershner and Helmstetter [61] suggests that AMY stimulation produces analgesia that is mediated in part by the release of opioid peptides within the ventral PAG. Microinjection of naloxone (an antagonist to opioid receptors) into the AMY can block EA-induced analgesia. [11]. Longchuan et al. demonstrated that the $\mathrm{HB}$ took part in the descending pathway of analgesia from ACB to PAG [62]. Wang et al. and Liu et al. found that the stimulation of $\mathrm{HB}$ induced an effect antagonist to the acupuncture analgesia through the inhibitory action in NRM. The ARC projects to PAG and LC [63-66]. Yin et al. reported that stimulation of the ARC significantly increased EAA and decreased EA-induced responses of neurons in the LC, which was reversed by i.p. injection of naloxone [67]. In present study, we found that the ARC, vlPAG, NRM, LC, and SDH were activated by EA at the set of Baihui and Santai or bilateral Housanli acupoints. It suggests that 
ARC-PAG-NRM/LC-SDH pathway is the common neural pathway activated by the two sets of acupoints. However, compared with EA at the set of bilateral Housanli acupoints, EA at the set of Baihui and Santai acupoints induced c-Fos-IR neurons to increase in $\mathrm{AB}$, but to decrease in $\mathrm{HL}$, suggesting different nuclei and areas of the limbic system can be activated by EA at different acupoints.

Several findings have shown that the hypothalamuspituitary system takes part in EA. Pan et al. [68] found that the low frequency electrical stimulation of the Zusanli acupoints caused marked expression of c-fos in the PG, as well as in the ARC and some nearby hypothalamic nuclei. Cho et al. demonstrated with fRMI that the hypothalamuspituitary system was excited after acupuncture and suggested a hypothesis that acupuncture analgesia is involved in the hypothalamus-pituitary system $[69,70]$. In present study, the increased expression of c-Fos was induced by EA at the set of Baihui and Santai acupoints and the set of bilateral Housanli acupoints in some hypothalamus nuclei (ARC and $\mathrm{VMH}$ ) and the PG. The results of the study provide additional evidence for participation of the hypothalamus-pituitary in EA regulation.

C-Fos expression is influenced by many factors. In laboratory animal experiment, acupuncture $[44,71]$, nociceptive stimulations [71, 72], and other stresses (restraint, noise, etc.) $[18,73]$ have been reported to upregulate $\mathrm{c}$-Fos expression in the spinal cord or brain areas. Ji et al. [71] compared the spinal c-Fos expressions caused by EA and the nociceptive stimulation and found that EA induced dense c-Fos-IR neurons in laminae III and IV whereas the nociceptive stimulation elicited significantly increased c-Fos-IR neurons in laminae I and II of the SDH in rats. In pathological conditions, cFos expression may be important for the development of a pain state as part of adaptive response of the spinal cord to nociceptive input [74]. Because EA can maintain homeostasis of the body $[75,76]$, it can suppress c-Fos expression in the $\mathrm{SDH}$ induced by the noxious stimulation, which has been demonstrated by numerous studies $[72,77,78]$. Pan et al. [79, 80] reported both EA and nociceptive stimulation increased c-Fos expression in PG and some hypothalamic nuclei, suggesting that there is probably a partial overlap of the central pathways caused by EA and noxious stimulation. In present study, all the animals were accustomed to the experimental conditions to reduce stress, and our results suggested the specific analgesia circuits induced by EA alone.

\section{Conclusion}

Potent analgesia was induced by EA stimulation at both the set of Baihui and Santai acupoints and the set of bilateral Housanli acupoints with stronger effect of the former than the latter. EA at the set of Baihui and Santai acupoints or bilateral Housanli acupoints induced more c-Fos-IR neurons in MSN, VMH, AB, ARC, HL, vlPAG, PBN, NRM, LC, GI, PG, and $\mathrm{SDH}$. The ARC-PAG-NRM/LC-SDH and the hypothalamuspituitary may be the common neural pathway activated by EA. The HB and AMY in the limbic system may be acupointdependent for EAA.

\section{Abbreviations}

AB: The nucleus amygdala basalis

ACB: The nucleus accumbens

AMY: The nucleus amygdala

ARC: The arcuate nucleus

CAU: The caudate nucleus

C-Fos-IR: c-Fos-like immunoreactive

CNS: The central nervous system

EA: Electroacupuncture

EAA: Electroacupuncture-induced analgesia

fMRI: Functional magnetic resonance imaging

GI: $\quad$ The gigantocellular reticular nucleus

HB: $\quad$ The habenula nucleus

HL: $\quad$ The lateral habenula nucleus

LC: The locus coeruleus

LSN: The lateral septal nucleus

MSN: The medial septal nucleus

NRM: The nucleus raphe magnus

NTS: The nucleus tractus solitaries

PAG: The periaqueductal grey

PBN: The parabrachial nucleus

PG: The anterior lobe of the pituitary gland

PVH: The paraventricular nucleus of the hypothalamus

RVM: $\quad$ Rostral ventromedial medulla

SDH: $\quad$ Spinal cord dorsal horn

SN: $\quad$ The septal nucleus

SNC: The substantia nigra

vlPAG: The ventrolateral periaqueductal grey

VMH: The ventromedial nucleus of the hypothalamus.

\section{Competing Interests}

No conflict of interests is declared by the authors. None of the authors have conflict of interests with the corporations and software mentioned in this paper.

\section{Acknowledgments}

This study is supported by the National Natural Science Foundation of China (nos. 31272619 and 31472246).

\section{References}

[1] S.-H. Lee and B.-C. Lee, "Electroacupuncture relieves pain in men with chronic prostatitis/chronic pelvic pain syndrome: three-arm randomized trial," Urology, vol. 73, no. 5, pp. 10361041, 2009.

[2] F. Qu and J. Zhou, "Electro-acupuncture in relieving labor pain," Evidence-Based Complementary and Alternative Medicine, vol. 4, no. 1, pp. 125-130, 2007.

[3] R. H. L. Wong, T. W. Lee, A. D. L. Sihoe et al., "Analgesic effect of electroacupuncture in postthoracotomy pain: a prospective randomized trial," The Annals of Thoracic Surgery, vol. 81, no. 6, pp. 2031-2036, 2006.

[4] W.-D. Xu, B. Zhu, P.-J. Rong, H. Bei, X.-Y. Gao, and Y.-Q. Li, "The pain-relieving effects induced by electroacupuncture with different intensities at homotopic and heterotopic acupoints in 
humans," The American Journal of Chinese Medicine, vol. 31, no. 5, pp. 791-802, 2003.

[5] H. Haltrecht, "Veterinary acupuncture," The Canadian Veterinary Journal, vol. 40, no. 6, pp. 401-403, 1999.

[6] J.-G. Lin and Y.-H. Chen, "The role of acupuncture in cancer supportive care," The American Journal of Chinese Medicine, vol. 40, no. 2, pp. 219-229, 2012.

[7] L. Vixner, L. B. Mårtensson, E. Stener-Victorin, and E. Schytt, "Manual and electroacupuncture for labour pain: study design of a longitudinal randomized controlled trial," Evidence-Based Complementary and Alternative Medicine, vol. 2012, Article ID 943198, 9 pages, 2012.

[8] J. Han, X. Ding, and S. Fan, "Frequency as the cardinal determinant for electroacupuncture analgesia to be reversed by opioid antagonists," Sheng Li Xue Bao, vol. 38, no. 5, pp. 475482, 1986.

[9] Q. Wang, L. Mao, and J. Han, “The arcuate nucleus of hypothalamus mediates low but not high frequency electroacupuncture analgesia in rats," Brain Research, vol. 513, no. 1, pp. 60-66, 1990.

[10] K. Liu, X.-Y. Gao, L. Li et al., "Neurons in the nucleus tractus solitarius mediate the acupuncture analgesia in visceral pain rats," Autonomic Neuroscience: Basic \& Clinical, vol. 186, pp. 9194, 2014.

[11] Z. F. Zhou, M. Y. Du, W. Y. Wu, Y. Jiang, and J. S. Han, "Effect of intracerebral microinjection of naloxone on acupuncture- and morphine-analgesia in the rabbit," Scientia Sinica, vol. 24, no. 8, pp. 1166-1178, 1981.

[12] H.-J. Du and Y.-F. Chao, "Effect of destruction or stimulation of locus coeruleus on inhibion of viscero-somatic reflex activities," Acta Physiological Sinica, vol. 2, article 5, 1979.

[13] J.-H. Chiu, M.-S. Chung, H.-C. Cheng et al., "Different central manifestations in response to electroacupuncture at analgesic and nonanalgesic acupoints in rats: a manganese-enhanced functional magnetic resonance imaging study," Canadian Journal of Veterinary Research, vol. 67, no. 2, pp. 94-101, 2003.

[14] W.-T. Zhang, Z. Jin, F. Luo, L. Zhang, Y.-W. Zeng, and J.-S. Han, "Evidence from brain imaging with fMRI supporting functional specificity of acupoints in humans," Neuroscience Letters, vol. 354, no. 1, pp. 50-53, 2004.

[15] B. Yan, K. Li, J. Xu et al., "Acupoint-specific fMRI patterns in human brain," Neuroscience Letters, vol. 383, no. 3, pp. 236-240, 2005.

[16] W. E. Cullinan, J. P. Herman, D. F. Battaglia, H. Akil, and S. J. Watson, "Pattern and time course of immediate early gene expression in rat brain following acute stress," Neuroscience, vol. 64, no. 2, pp. 477-505, 1995.

[17] C. V. Dayas, K. M. Buller, J. W. Crane, Y. Xu, and T. A. Day, "Stressor categorization: acute physical and psychological stressors elicit distinctive recruitment patterns in the amygdala and in medullary noradrenergic cell groups," European Journal of Neuroscience, vol. 14, no. 7, pp. 1143-1152, 2001.

[18] S. Campeau and S. J. Watson, "Neuroendocrine and behavioral responses and brain pattern of c-fos induction associated with audiogenic stress," Journal of Neuroendocrinology, vol. 9, no. 8, pp. 577-588, 1997.

[19] K. Pacák and M. Palkovits, "Stressor specificity of central neuroendocrine responses: implications for stress-related disorders," Endocrine Reviews, vol. 22, no. 4, pp. 502-548, 2001.

[20] I. H. Miklós and K. J. Kovács, "Functional heterogeneity of the responses of histaminergic neuron subpopulations to various stress challenges," European Journal of Neuroscience, vol. 18, no. 11, pp. 3069-3079, 2003.
[21] W. Fu, S. R. Shah, H. Jiang, D. C. Hilt, H. P. G. Dave, and J. B. Joshi, "Transactivation of proenkephalin gene by HTLV-1 $\operatorname{tax}_{1}$ protein in glial cells: involvement of Fos/Jun complex at an AP-1 element in the proenkephalin gene promoter," Journal of Neurovirology, vol. 3, no. 1, pp. 16-27, 1997.

[22] M. Comb, N. Mermod, S. E. Hyman, J. Pearlberg, M. E. Ross, and H. M. Goodman, "Proteins bound at adjacent DNA elements act synergistically to regulate human proenkephalin cAMP inducible transcription," The EMBO Journal, vol. 7, no. 12, pp. 3793-3805, 1988.

[23] D. Becquet, F. Guillaumond, O. Bosler, and A. M. FrançoisBellan, "Long-term variations of AP-1 composition after CRH stimulation: consequence on POMC gene regulation," Molecular and Cellular Endocrinology, vol. 175, no. 1-2, pp. 93-100, 2001.

[24] D. J. Autelitano, "Stress-induced stimulation of pituitary POMC gene expression is associated with activation of transcription factor AP-1 in hypothalamus and pituitary," Brain Research Bulletin, vol. 45, no. 1, pp. 75-82, 1998.

[25] J. Naranjo, B. Mellström, M. Achaval, and P. Sassone-Corsit, "Molecular pathways of pain: Fos/Jun-mediated activation of a noncanonical AP-1 site in the prodynorphin gene," Neuron, vol. 6, no. 4, pp. 607-617, 1991.

[26] S. J. Garlow and R. D. Ciaranello, "Transcriptional control of the rat serotonin-2 receptor gene," Molecular Brain Research, vol. 31, no. 1-2, pp. 201-209, 1995.

[27] H.-J. Monstein, "Identification of an AP-1 transcription factor binding site within the human cholecystokinin (CCK) promoter," NeuroReport, vol. 4, no. 2, pp. 195-197, 1993.

[28] D.-M. Liu, Z.-Y. Zhou, Y. Ding et al., "Physiologic effects of electroacupuncture combined with intramuscular administration of xylazine to provide analgesia in goats," American Journal of Veterinary Research, vol. 70, no. 11, pp. 1326-1332, 2009.

[29] J. Han, "Acupuncture anesthesia (AA) versus acupunctureassisted anesthesia (AAA)," Acupuncture Research, vol. 22, pp. 97-101, 1997.

[30] G.-L. Qu, X.-L. Zhuang, G.-H. Xu et al., "Clinical observation on combined anesthetics acupuncture anesthesia in 50 patients undergoing renal transplantation," Chinese Journal of Pain Medicine, vol. 2, pp. 72-77, 1996.

[31] Z.-Y. Qiu, Y. Ding, L.-Y. Cui, M.-L. Hu, and M.-X. Ding, "The expression patterns of c-Fos and c-Jun induced by different frequencies of electroacupuncture in the brain," Evidence-Based Complementary and Alternative Medicine, vol. 2015, Article ID 343682, 10 pages, 2015.

[32] L.-L. Cheng, M.-X. Ding, J. Wei et al., "Electroacupunctureinduced dynamic processes of gene expression levels of endogenous opioid peptide precursors and opioid receptors in the CNS of goats," Evidence-Based Complementary and Alternative Medicine, vol. 2013, Article ID 257682, 10 pages, 2013.

[33] L.-L. Cheng, M.-X. Ding, C. Xiong, M.-Y. Zhou, Z.-Y. Qiu, and Q. Wang, "Effects of electroacupuncture of different frequencies on the release profile of endogenous opioid peptides in the central nerve system of goats," Evidence-Based Complementary and Alternative Medicine, vol. 2012, Article ID 476457, 9 pages, 2012.

[34] G. A. Ulett, S. Han, and J.-S. Han, "Electroacupuncture: mechanisms and clinical application," Biological Psychiatry, vol. 44, no. 2, pp. 129-138, 1998.

[35] S. A. Humphries, N. R. Long, and M. H. Johnson, "Iontophoretically applied potassium ions as an experimental pain stimulus for investigating pain mechanisms," Perception \& Psychophysics, vol. 56, no. 6, pp. 637-648, 1994. 
[36] J. S. Tindal, A. Turvey, and L. A. Blake, "A stereotaxic atlas of the medulla oblongata of the goat's brain," Journal of Anatomy, vol. 155, pp. 195-202, 1987.

[37] J. S. Tindal, G. S. Knaggs, and A. Turvey, "The forebrain of the goat in stereotaxic coordinates," Journal of Anatomy, vol. 103, no. 3, pp. 457-469, 1968.

[38] C. Dean, L. K. Geiger, B. M. Sprtel, P. J. Ohtake, and H. V. Forster, "An anatomic atlas of the medulla oblongata of the adult goat," Journal of Applied Physiology, vol. 87, no. 3, pp. 1220-1229, 1999.

[39] B. Félix, M.-E. Léger, D. Albe-Fessard et al., "Stereotaxic atlas of the pig brain," Brain Research Bulletin, vol. 49, no. 1-2, pp. 1-137, 1999.

[40] X. Wang, Z. Zhou, and J. Han, "Frequency of electroacupuncture as a cardinal factor determining the potency of analgesia and its vulnerability to naloxone blockade in rabbits," Zhen ci Yan Jiu, vol. 13, no. 1, pp. 56-60, 1987.

[41] K. Wang, X.-H. Xiang, N. Qiao et al., "Genomewide analysis of rat periaqueductal gray-dorsal horn reveals time-, regionand frequency-specific mRNA expression changes in response to electroacupuncture stimulation," Scientific Reports, vol. 4, article 6713, 2014.

[42] W. Cao, Y. Deng, X. Dong, Y. Wang, and Z. Lu, "Effects of electroacupuncture at different frequencies on the nociceptive response and central contents of GABA and glutamic acid in arthritic rats," Zhen Ci Yan Jiu, vol. 18, no. 1, pp. 48-52, 1993.

[43] K. K. S. Hui, J. Liu, O. Marina et al., “The integrated response of the human cerebro-cerebellar and limbic systems to acupuncture stimulation at ST 36 as evidenced by fMRI," NeuroImage, vol. 27, no. 3, pp. 479-496, 2005.

[44] L. Jang-Hern and A. J. Beitz, "The distribution of brain-stem and spinal cord nuclei associated with different frequencies of electroacupuncture analgesia," Pain, vol. 52, no. 1, pp. 11-28, 1993.

[45] Y. Chae, C. H. Yang, Y. K. Kwon et al., "Acupuncture attenuates repeated nicotine-induced behavioral sensitization and c-Fos expression in the nucleus accumbens and striatum of the rat," Neuroscience Letters, vol. 358, no. 2, pp. 87-90, 2004.

[46] M. J. Millan, "Descending control of pain," Progress in Neurobiology, vol. 66, no. 6, pp. 355-474, 2002.

[47] J.-S. Han, G. Xie, Z. Zhou, R. Folkesson, and L. Terenius, "Acupuncture mechanisms in rabbits studied with microinjection of antibodies against $\beta$-endorphin, enkephalin and substance P," Neuropharmacology, vol. 23, no. 1, pp. 1-5, 1984.

[48] G. X. Xie, J. S. Han, and V. Höllt, "Electroacupuncture analgesia blocked by microinjection of anti-beta-endorphin antiserum into periaqueductal gray of the rabbit," International Journal of Neuroscience, vol. 18, no. 3-4, pp. 287-291, 1983.

[49] A. I. Basbaum and H. L. Fields, "Endogenous pain control systems: brainstem spinal pathways and endorphin circuitry," Annual Review of Neuroscience, vol. 7, no. 1, pp. 309-338, 1984.

[50] M. Ennis, M. Behbehani, M. T. Shipley, E. J. van Bockstaele, and G. Aston-Jones, "Projections from the periaqueductal gray to the rostromedial pericoerulear region and nucleus locus coeruleus: anatomic and physiologic studies," Journal of Comparative Neurology, vol. 306, no. 3, pp. 480-494, 1991.

[51] S. S. Mokha, J. A. McMillan, and A. Iggo, "Pathways mediating descending control of spinal nociceptive transmission from the nuclei locus coeruleus (LC) and raphe magnus (NRM) in the cat," Experimental Brain Research, vol. 61, no. 3, pp. 597-606, 1986.
[52] M. Ao, J. Wei, Z. Tan, Q. Hu, and J. Tang, "The influence of electroacupuncture with different frequencies on the discharges of neurons in rostral ventromedial medulla on rats," Zhen Ci Yan Jiu, vol. 21, no. 4, pp. 41-45, 1996.

[53] A. Li, Y. Wang, J. Xin et al., "Electroacupuncture suppresses hyperalgesia and spinal Fos expression by activating the descending inhibitory system," Brain Research, vol. 1186, no. 1, pp. 171-179, 2007.

[54] R. W. Hurley, P. Banfor, and D. L. Hammond, "Spinal pharmacology of antinociception produced by microinjection of $\mu$ or $\delta$ opioid receptor agonists in the ventromedial medulla of the rat," Neuroscience, vol. 118, no. 3, pp. 789-796, 2003.

[55] J. Fang, Z. Jin, Y. Wang et al., "The salient characteristics of the central effects of acupuncture needling: limbic-paralimbicneocortical network modulation," Human Brain Mapping, vol. 30, no. 4, pp. 1196-1206, 2009.

[56] Y. Sun, J. Fang, E. Nixon et al., "Dynamic response of the human brain to acupuncture at LV3 as monitored by fMRI Evidence of limbic system modulation," Neuroimage, vol. 31, p. S161, 2006.

[57] V. Napadow, N. Kettner, J. Liu et al., "Hypothalamus and amygdala response to acupuncture stimuli in carpal tunnel syndrome," Pain, vol. 130, no. 3, pp. 254-266, 2007.

[58] D. A. Hopkins and G. Holstege, "Amygdaloid projections to the mesencephalon, pons and medulla oblongata in the cat," Experimental Brain Research, vol. 32, no. 4, pp. 529-547, 1978.

[59] T. A. Rizvi, M. Ennis, M. M. Behbehani, and M. T. Shipley, "Connections between the central nucleus of the amygdala and the midbrain periaqueductal gray: topography and reciprocity," Journal of Comparative Neurology, vol. 303, no. 1, pp. 121-131, 1991.

[60] A. A. Cameron, I. A. Khan, K. N. Westlund, and W. D. Willis, "The efferent projections of the periaqueductal gray in the rat: a Phaseolus vulgaris-leucoagglutinin study. II. Descending projections," Journal of Comparative Neurology, vol. 351, no. 4, pp. 585-601, 1995.

[61] S. A. Tershner and F. J. Helmstetter, "Antinociception produced by mu opioid receptor activation in the amygdala is partly dependent on activation of mu opioid and neurotensin receptors in the ventral periaqueductal gray," Brain Research, vol. 865, no. 1, pp. 17-26, 2000.

[62] Y. Longchuan, S. Yushun, and H. Jisheng, "A descending pathway of analgesia from nucleus accumbens to habenula," Science Bulletin (Beijing), vol. 33, no. 4, pp. 337-341, 1988.

[63] H. Akil, S. J. Watson, E. Young, M. E. Lewis, H. Khachaturian, and J. M. Walker, "Endogenous opioids: biology and function," Annual Review of Neuroscience, vol. 7, no. 1, pp. 223-255, 1984.

[64] F. Bloom, E. Battenberg, J. Rossier, N. Ling, and R. Guillemin, "Neurons containing $\beta$-endorphin in rat brain exist separately from those containing enkephalin: immunocytochemical studies," Proceedings of the National Academy of Sciences of the United States of America, vol. 75, no. 3, pp. 1591-1595, 1978.

[65] S. Wang, Y. Jiang, J. S. Xiao, M. Liu, and S. Liu, "Spontaneous discharges of habenular nucleus and its inhibitory action on nucleus raphe magnus," Science Bulletin, vol. 25, pp. 83-88, 1980.

[66] G. Liu and S. Wang, "Effects of nucleus raphe magnus and locus coeruleus in descending modulation of the habenula on pain threshold and acupuncture analgesia," Acta Pharmacologica Sinica, vol. 9, no. 1, pp. 18-22, 1988.

[67] Q. Yin, J. Mao, and S. Guo, "Changes of reactions of neurones in dorsal raphe nucleus and locus coeruleus to electroacupuncture by hypothalamic arcuate nucleus stimulation," Functional Neurology, vol. 3, no. 3, pp. 263-273, 1988. 
[68] B. Pan, J. M. Castro-Lopes, and A. Coimbra, "C-fos expression in the hypothalamo-pituitary system induced by electroacupuncture or noxious stimulation," NeuroReport, vol. 5, no. 13, pp. 1649-1652, 1994.

[69] Z. H. Cho, S. C. Hwang, E. K. Wong et al., "Neural substrates, experimental evidences and functional hypothesis of acupuncture mechanisms," Acta Neurologica Scandinavica, vol. 113, no. 6, pp. 370-377, 2006.

[70] Z. H. Cho, S. C. Chung, H. J. Lee, E. K. Wong, and B. I. Min, "Retraction. New findings of the correlation between acupoints and corresponding brain cortices using functional MRI," Proceedings of the National Academy of Sciences of the United States of America., vol. 103, no. 27, p. 10527, 2006.

[71] R. Ji, X. Wang, and J. Han, "Induction of Fos-like protein in the rat spinal cord following electroacupuncture stimulation," Sheng Li Xue Bao, vol. 44, no. 4, pp. 394-400, 1992.

[72] A. T. A. Gonçalves de Freitas, L. Lemonica, J. De Faveri, S. Pereira, and M. D. Bedoya Henao, "Preemptive analgesia with acupuncture monitored by c-Fos expression in rats," Journal of Acupuncture and Meridian Studies, vol. 9, no. 1, pp. 16-21, 2016.

[73] J. Zhao, Z. Wang, B. Zou, Y. Song, and L. Dong, "Camostat mesilate, a protease inhibitor, inhibits visceral sensitivity and spinal c-fos expression in rats with acute restraint stress," Nan Fang Yi Ke Da Xue Xue Bao, vol. 34, no. 10, pp. 1546-1550, 2014.

[74] G. Draisci and M. J. Iadarola, "Temporal analysis of increases in c-fos, preprodynorphin and preproenkephalin mRNAs in rat spinal cord," Molecular Brain Research, vol. 6, no. 1, pp. 31-37, 1989.

[75] D. M. Hau, "Effects of electroacupuncture on leukocytes and plasma protein in the X-irradiated rats," The American Journal of Chinese Medicine, vol. 12, no. 1-4, pp. 106-114, 1984.

[76] Y.-H. Luo, G.-W. Zhong, S.-P. Zhao, H.-M. Tang, and L.-N. Zhang, "Efficacy observation of electroacupuncture intervention on severe acute pancreatitis at early stage complicated with intestinal paralysis," Chinese Acupuncture \& Moxibustion, vol. 31, no. 2, pp. 105-109, 2011.

[77] J.-H. Lee and A. J. Beitz, "Electroacupuncture modifies the expression of c-fos in the spinal cord induced by noxious stimulation," Brain Research, vol. 577, no. 1, pp. 80-91, 1992.

[78] Y.-J. Zeng, S.-Y. Tsai, K.-B. Chen, S.-F. Hsu, J. Y.-R. Chen, and Y.-R. Wen, "Comparison of electroacupuncture and morphinemediated analgesic patterns in a plantar incision-induced pain model," Evidence-Based Complementary and Alternative Medicine, vol. 2014, Article ID 659343, 12 pages, 2014.

[79] B. Pan, J. M. Castro-Lopes, and A. Coimbra, "Chemical sensory deafferentation abolishes hypothalamic pituitary activation induced by noxious stimulation or electroacupuncture but only decreases that caused by immobilization stress. A c-fos study," Neuroscience, vol. 78, no. 4, pp. 1059-1068, 1997.

[80] B. Pan, J. M. Castro-Lopes, and A. Coimbra, "Activation of anterior lobe corticotrophs by electroacupuncture or noxious stimulation in the anaesthetized rat, as shown by colocalization of fos protein with ACTH and $\beta$-endorphin and increased hormone release," Brain Research Bulletin, vol. 40, no. 3, pp. 175182, 1996. 


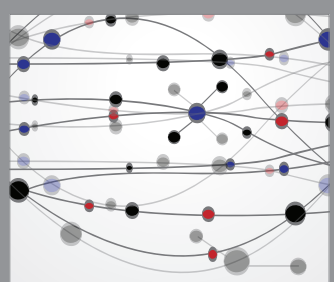

The Scientific World Journal
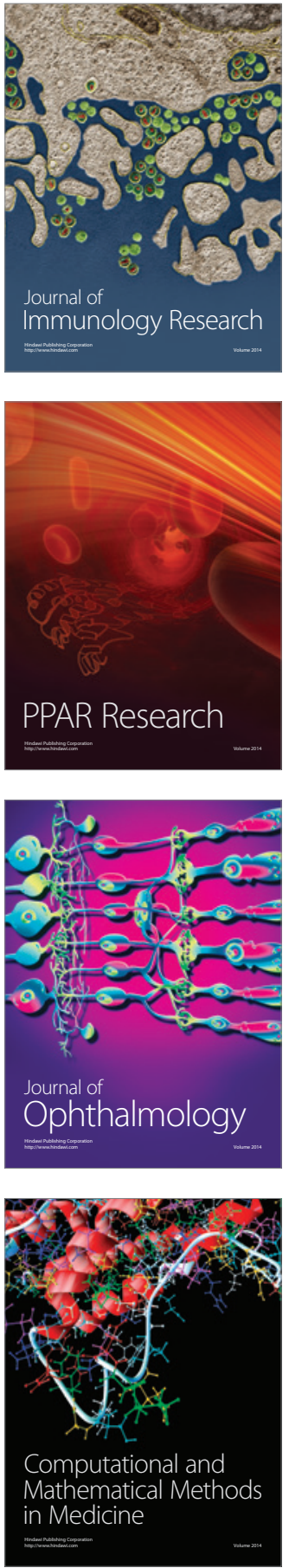

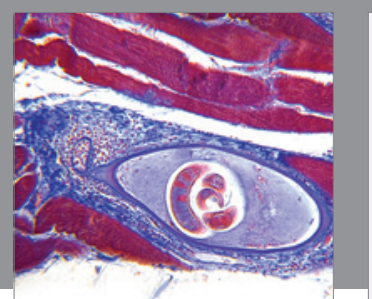

Gastroenterology Research and Practice

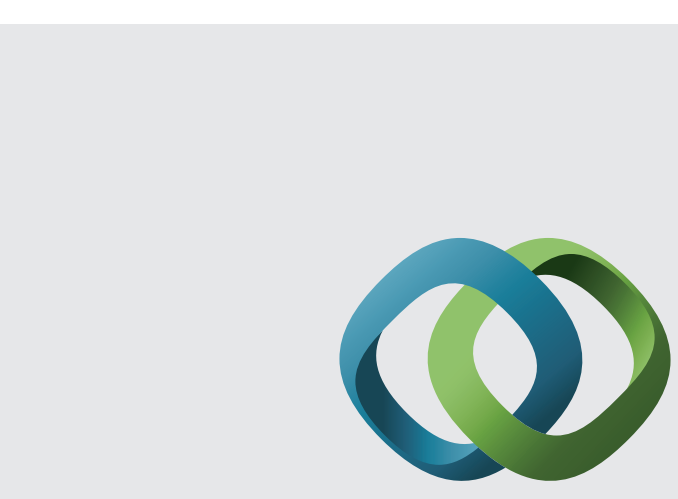

\section{Hindawi}

Submit your manuscripts at

http://www.hindawi.com
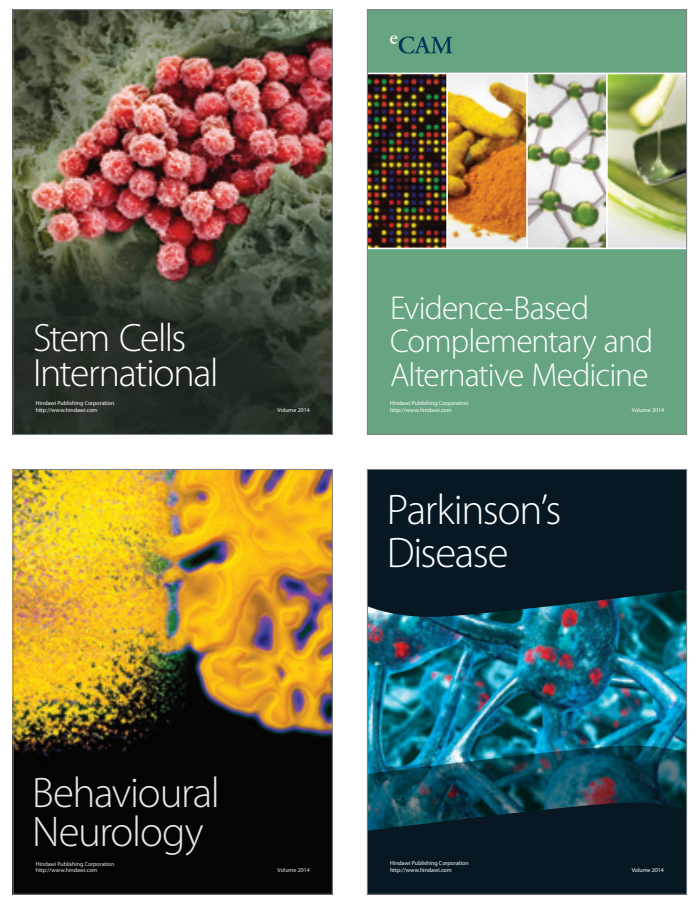
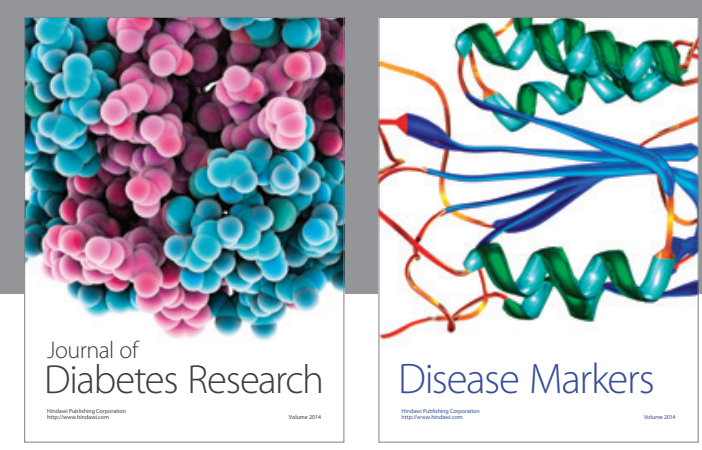

Disease Markers
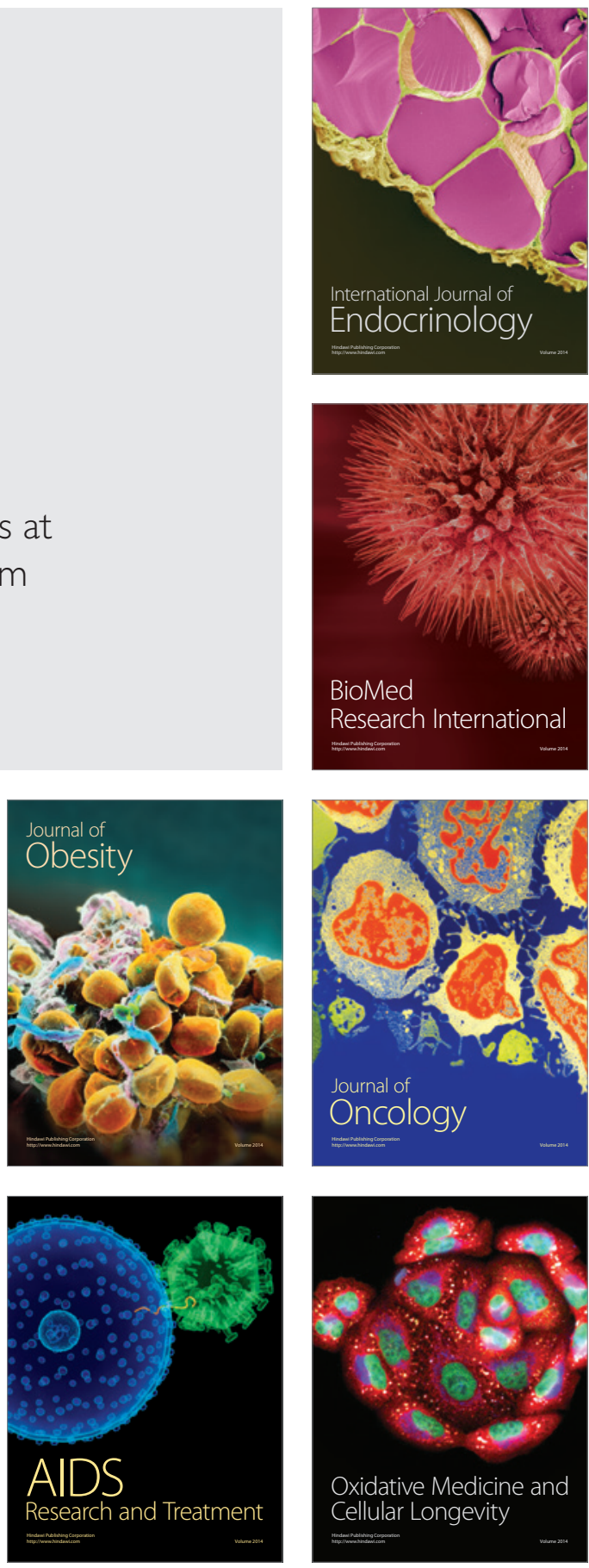